\title{
DÉFICIT HABITACIONAL CUALITATIVO: UNA APROXIMACIÓN PARA EL CASO BOLIVIANO
}

Natali Escalera Nava and Pamela Córdova Olivera

\section{RESUMEN}

El Déficit Habitacional en Bolivia ha sido estudiado en distintas áreas de conocimiento, con el objetivo principal de conocer la brecha existente entre el requerimiento de los hogares en cuanto a viviendas (Déficit Habitacional Cuantitativo) y el estado de las mismas (Déficit Habitacional Cualitativo). El presente trabajo se concentra específicamente en el estudio del Déficit Habitacional Cualitativo y comprende tres etapas de análisis, la primera aproxima de manera estadística el Déficit Habitacional Cualitativo para Bolivia al año 2014, caracterizando a las viviendas de los hogares a nivel nacional, por área de residencia (urbano y rural) y a nivel departamental. En la segunda se realiza el cálculo del Déficit para el año 2014 identificando además el grado de Déficit presente. En la tercera y última etapa y con el fin de establecer evidencia empírica que explique los determinantes de la probabilidad de sufrir Déficit Habitacional Cualitativo por parte de los hogares bolivianos, se procedió a la estimación de un moldeo PROBIT para el año 2014 (sector urbano), que permitió la caracterización completa de las viviendas que presentan Déficit aproximándolo a partir de los datos reportados en la encuesta de hogares del año 2014.

Palabras clave: Déficit Habitacional Cualitativo, Modelo PROBIT, Caracterización de Viviendas. 